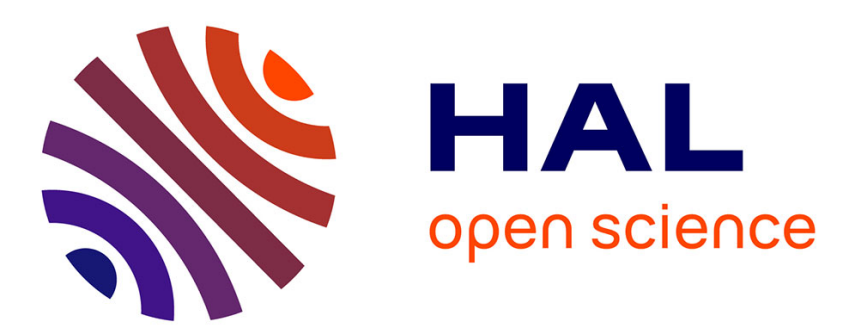

\title{
Prioritization of habitat patches for landscape connectivity conservation differs between least-cost and resistance distances
}

\author{
C. Avon, L. Bergès
}

\section{- To cite this version:}

C. Avon, L. Bergès. Prioritization of habitat patches for landscape connectivity conservation differs between least-cost and resistance distances. Landscape Ecology, 2016, 31 (7), pp.1551-1565. 10.1007/s10980-015-0336-8 . hal-01393253

\section{HAL Id: hal-01393253 \\ https://hal.science/hal-01393253}

Submitted on 7 Nov 2016

HAL is a multi-disciplinary open access archive for the deposit and dissemination of scientific research documents, whether they are published or not. The documents may come from teaching and research institutions in France or abroad, or from public or private research centers.
L'archive ouverte pluridisciplinaire HAL, est destinée au dépôt et à la diffusion de documents scientifiques de niveau recherche, publiés ou non, émanant des établissements d'enseignement et de recherche français ou étrangers, des laboratoires publics ou privés. 


\section{Title page}

Prioritization of habitat patches for landscape connectivity conservation differs between

least-cost and resistance distances

Catherine Avon ${ }^{1 *}$, Laurent Bergès ${ }^{1}$

*Corresponding author e-mail: catherine.avon@hotmail.fr

${ }^{1}$ UR EMAX, Irstea, 3275 Route Cézanne, CS 40061, F-13182 Aix-en-Provence, France

Date of manuscript draft: 07/07/15

Word count (ms revised 2, December 2015): 6579 (without Supporting Material) 


\section{Abstract}

2 Context. Methods quantifying habitat patch importance for maintaining habitat network connectivity have been emphasized in helping to prioritize conservation actions. Functional connectivity is accepted as depending on landscape resistance, and several measures of

5 functional inter-patch distance have been designed. However, how the inter-patch distance, i.e. based on least-cost path or multiple paths, influences the identification of key habitat

7 patches has not been explored.

Objectives. We compared the prioritization of habitat patches according to least-cost distance (LCD) and resistance distance (RD), using common binary and probabilistic connectivity metrics.

Methods. Our comparison was based on a generic functional group of forest mammals with different dispersal distances, and was applied to two landscapes differing in their spatial extent and fragmentation level.

Results. We found that habitat patch prioritization did not depend on distance type when considering the role of patch as contributing to dispersal fluxes. However, the role of patch as a connector facilitating dispersal might be overestimated by LCD-based indices compared with RD for short- and medium-distance dispersal. In particular, when prioritization was based on dispersal probability, the consideration of alternatives routes identified the connectors that probably provided functional connectivity for species in the long term. However, the use of LCD might help identify landscape areas that need critical restoration to

21 improve individual dispersal.

22 Conclusions. Our results provide new insights about the way that inter-patch distance is 23 viewed changes the evaluation of functional connectivity. Accordingly, prioritization 
24 methods should be carefully selected according to assumptions about population

25 functioning and conservation aims.

27 Keywords. habitat network connectivity; graph theory; connectivity indices; least-cost path;

28 resistance distance; circuit theory; landscape resistance; species dispersal; landscape

29 fragmentation; habitat patch importance 


\section{Introduction}

Landscape connectivity is accepted as being crucial for biodiversity conservation, because land-use changes and habitat fragmentation per se can dramatically damage species' habitats and species' dispersal. The way a landscape allows or impedes movement of species determines the fluxes of individuals or genes that are exchanged between habitat patches, which help to maintain populations and metapopulations (Verbeylen et al. 2003; Stevens et al. 2006; Amos et al. 2014). Recently, applications of graph theory to landscape ecology have shown potential for quantifying the connectivity of landscape for a species or species group by focusing on the role of habitat patches and dispersal linkages between them (PascualHortal and Saura 2006; McRae and Beier 2007; Pinto and Keitt 2009; Rayfield et al. 2011). In particular, researchers have developed methods to identify the most important habitat patches for maintaining the global connectivity of habitat networks (Pascual-Hortal and Saura 2006; Urban et al. 2009; Bodin and Saura 2010; Saura and Rubio 2010; Ernst 2014). These prioritization methods are thought to be particularly useful for conservation biologists and landscape managers: they can guide the location of future finer-scale studies and help to define conservation, restoration or mitigation measures that should favour a better (spatial) allocation of funds and efforts to protect biodiversity (Zetterberg et al. 2010; Foltete et al. 2014; Gurrutxaga and Saura 2014).

Habitat patch prioritization based on landscape graphs uses connectivity indices that quantify the importance of each habitat patch for habitat network connectivity, taking into account its position in the habitat network with, for example, centrality indices (e.g. Estrada and Bodin 2008). But, connectivity indices generally consider both the position and the quality (or quantity) of available habitat such as the Integral Index of Connectivity (IIC) and 
Author-produced version of the article published in Landscape Ecology, 2016, 31, 7, 1551-1565

The original publication is available at http://link.springer.com/article/10.1007/s10980-015-0336-8 DOI: 10.1007/s10980-015-0336-8

53

the Probability of Connectivity index (PC) (Pascual-Hortal and Saura 2006; Saura and PascualHortal 2007; Saura and Rubio 2010). These connectivity indices make a compromise between the effects of landscape composition and landscape structure on species presence, a question still debated in the literature (Didham et al. 2012). Different attributes of habitat patches can be used to consider habitat patch quality: this can depend on species requirements, but more often on the information available, often justifying the use of proxies of habitat patch quality calculated from landscape maps such as patch area, patch interior area or level of anthropogenization. How well one habitat patch is linked to the rest of the habitat network depends on the distance between this habitat patch and the other patches, but the way in which the method used to calculate this distance affects the degree of connectivity of habitat patches remains unclear. Traditionally in graph theory, distance between habitat patches was just the topological distance, i.e. Euclidean distance, but in this last decade many studies on animal dispersal movement have shown that Euclidean distance is not realistic because it does not integrate the difficulty or mortality encountered by a species moving through a landscape mosaic (Adriaensen et al. 2003; Belisle 2005). Many efforts have been made to integrate landscape resistance more fully with species movement, and two methods are now widely used to quantify the distance a species has to travel to disperse between habitat patches.

The classical least-cost path is based on friction maps reflecting the difficulty for a species to move between two source patches (Adriaensen et al. 2003). A species accumulates a cost with increasing distance from source patches, depending on its dispersal capacities and specific habitat encountered. The least-cost distance (LCD) is the accumulated cost distance of the most likely route an individual would take to move between the two habitat patches considered, i.e. the least-cost path (LCP). However, LCP implies that species 
Author-produced version of the article published in Landscape Ecology, 2016, 31, 7, 1551-1565

The original publication is available at http://link.springer.com/article/10.1007/s10980-015-0336-8 DOI: 10.1007/s10980-015-0336-8

know the optimal path to get to a new habitat patch, and a major criticism is that it does not take into account the existence of other optimal paths, whereas species generally use random or alternative dispersal routes depending on individual behaviour (Belisle 2005). Nevertheless, LCD itself indicates the minimum distance separating the individual habitat patches and so the reachability of habitat for species. LCD is therefore now preferred to Euclidean distance for parameterizing connectivity indices prioritizing habitat patch importance (Zetterberg et al. 2010; Gurrutxaga et al. 2011; Clauzel et al. 2013). A recent significant advance in quantifying resistance distance separating habitat patches was provided by circuit theory, which takes into account random movement paths and path redundancy (McRae and Beier 2007; McRae et al. 2008). An electric current flowing through landscape resistance maps represents species dispersal flux at each point of the landscape: all the alternative paths between two habitat patches are used to calculate resistance distance (RD), which represents the effective distance separating the two habitat patches for a species. The more alternative paths there are, the shorter RD is compared to LCD. RD has been particularly widely used in genetic studies to evaluate functional landscape connectivity by correlating RD to genetic distance between population patches (Amos et al. 2014; Marrotte et al. 2014), and current maps are considered to identify dispersal corridors well (Roever et al. 2013). Some studies have used both LCD and RD (or resulting maps) to find out which is the better predictor of species movement corridors (Poor et al. 2012; LaPoint et al. 2013) or how they change with cost map parameterization (Koen et al. 2012). One recent study (Ayram et al. 2014) used both LCD and circuit theory to identify important landscape elements: IIC index was based on LCD to determine key habitat patches, and current maps were used to locate corridors for two mammal species. However, to our knowledge, how LCD and RD influence patch importance and the identification of key 
Author-produced version of the article published in Landscape Ecology, 2016, 31, 7, 1551-1565

The original publication is available at http://link.springer.com/article/10.1007/s10980-015-0336-8 DOI: $10.1007 / \mathrm{s} 10980-015-0336-8$

101

102

103

104

105

elements maintaining habitat network connectivity has never been studied. It remains unclear whether the modelling of alternative paths, which is very time-consuming, is really required to identify key elements for habitat connectivity, or whether the modelling of the one best path, which is faster, is sufficient to approximate habitat patch importance adequately.

\section{based on LCP and from graph models based on RD. We used binary and probabilistic}

connectivity indices, i.e. Betweenness Centrality (BC), patch importance based on Integral Index of Connectivity (dIIC) and based on Probability of Connectivity (dPC), in order to provide support in the use of the most commonly employed connectivity indices in conservation studies. We hypothesized that the identification of key habitat patches would tend to agree with increasing dispersal distance, but that identification could remain different in certain cases, particularly when the probability of dispersal was considered, since RD integrates multiple paths unlike LCD. We go on to discuss ecological hypotheses that might explain these differences. Our comparison is based on two real landscapes (e.g. Koen et al. 2010; Koen et al. 2012) ranging in habitat cover, fragmentation level, and spatial extent to verify consistency of relationship with landscape structure. Habitat patch prioritization focused on forest mammal species with different dispersal distances using a generic approach and following a conservation perspective, not a restoration or mitigation perspective. In this case, habitat patch prioritization aims to evaluate the importance of each habitat patch for maintaining the global connectivity of the habitat network for the species. 


\section{Study area and land cover map}

125 Two study cases were selected in the South of France $\left(43^{\circ} 01^{\prime}-45^{\circ} 07^{\prime} \mathrm{N}\right.$ and $\left.4^{\circ} 13^{\prime}-7^{\circ} 43^{\prime} \mathrm{E}\right)$.

126 The first study case, hereafter named "Region", followed the administrative boundaries of

127 Region PACA, excluding isolated parts (e.g. Mediterranean islands) and encompassed about

$12831700 \mathrm{~km}^{2}$. Region was mainly covered by forests (38\%), other semi-natural and natural

129 areas (35\%), agricultural areas (17\%) and artificial areas (7\%); other areas were wetlands and

130 water bodies (3\%). A second landscape hereafter named "Sub-region" was a sub-area of

131 about $7090 \mathrm{~km}^{2}$, and contained strong human-created barriers. Sub-region was affected by a

132 higher level of anthropogenization than Region, with a lower cover of forests and other

133 semi-natural and natural areas ( $27 \%$ and $26 \%$ respectively), and a higher cover of agricultural

134 areas and artificial areas (31\% and $11 \%$ respectively). Other areas were wetlands and water

135 bodies (3\%). The study area was bordered by the Alps at the East, anthropogenized areas at

136 the West and the Mediterranean Sea at the South. Landscape habitats came from the map

137 ocsol2006 of Crige PACA (www.crige-paca.org), an adaptation of the CORINE land cover

138 nomenclature of the European Environmental Agency (http://www.eea.europa.eu/data-

139 and-maps) for French Mediterranean landscapes with a smaller spatial resolution. The land

140 cover map identified 42 types of landscape features, including natural and human-

141 dominated lands, highways and major railways, with a minimal mapping unit varying from

1420.5 to 2.5 ha. 


\section{Functional group approach}

145 We focused on generalist forest mammal species using a generic approach for our

connectivity models, because these species depend on a well-defined habitat and are known

147 to be sensitive to landscape features of interest for land managers, such as transportation

148 infrastructures, and urban and other anthropogenized areas. We collected scientific

149 literature on forest mammal species and consulted studies using a generic forest species approach (Verbeylen et al. 2003; Watts et al. 2010; Garcia-Feced et al. 2011; Gurrutxaga et al. 2011; Gimona et al. 2012) to determine the resistance of landscape features to animal movement. The attribution of cost values to landscape features is still under debate (Zeller et al. 2012; Mateo-Sanchez et al. 2015) and would be based on ad hoc data, i.e. showing species dispersal movement (pathways data), in the ideal but very uncommon case. connectivity between forest habitat patches, such as that of Verbeylen et al. (2003), who tested a range of cost values and cost classes to find the best combination explaining the

158 presence of forest species in forest habitat patches. Our review caused the original land 159 cover map to turn into a landscape resistance map with five cost classes: 1 for forest areas 160 (species habitat), 10 for less open areas with trees (or potential feeding-seed trees), 300 for 161 more open areas including shrubs or gardens, 800 for areas with low vegetation such as agricultural lands, and 1000 for landscape features that most impeded animal movement such as highways, buildings and permanent snow. We then rasterized the cost map at a 100 m pixel size to reduce calculation time for analysis (McRae et al. 2008). Habitat patches were

165 defined as entirely covered by forest, up to the upper tree-line at $2100 \mathrm{~m}$ a.s.l. and with a 166 surface area of at least 10 ha. We kept 621 forest habitat patches for Sub-region and 2482 167 forest habitat patches for Region. GIS calculations were performed with ArcGis $10\left(E S R I^{\circledR}\right)$. 


\section{Least-cost distance and resistance distance}

170 Linkages were modelled between habitat patches using a maximum distance according to

171 species dispersal capacities and the extent of the study area. For connectivity analyses (see

172 below), we used a range of distances rather than only one, enabling us to take into account

173 information disparity in the literature and variation in species dispersal distance (e.g.

174 juvenile dispersal, adult dispersal, long-distance dispersal events). Most importantly, this

175 enabled us to analyse how our connectivity models changed with dispersal distance and so

176 to what extent LCP-based prioritization is correlated to RD-based prioritization. Our review

177 prompted us to use the following dispersal distances (edge-to-edge of habitat patches): 200

$178 \mathrm{~m}, 700 \mathrm{~m}, 1000 \mathrm{~m}, 4000 \mathrm{~m}, 6000 \mathrm{~m}, 10 \mathrm{~km}, 15 \mathrm{~km}, 20 \mathrm{~km}$ and $25 \mathrm{~km}$. Our connectivity

179 models thus considered a range of dispersal distances ranging from $200 \mathrm{~m}$ to $25 \mathrm{~km}$,

180 enabling us to consider short-, medium- and long-distance dispersal of forest mammal

181 species. The maximum dispersal distance of $25 \mathrm{~km}$ yielded 898 linkages for Sub-region and

1823399 for Region. In this article, dispersal distance was in kilometres but it was actually a cost

183 distance: in the analyses, dispersal distance was multiplied by the median value of the cost

184 raster to reflect the cost of the path travelled by the species (e.g. Gurrutxaga et al. 2011). A

185 species moves a larger geographical distance through permeable landscape features than

186 through landscape features with high resistance. Dispersal distances stated in the literature

187 often result from straight-line distance calculations between pre- and post-dispersal habitat

188 patches (e.g. Wauters et al. 2010), whereas species had actually moved through different

189 landscape features along a much longer non-linear path (Rowcliffe et al. 2012). 
Author-produced version of the article published in Landscape Ecology, 2016, 31, 7, 1551-1565

The original publication is available at http://link.springer.com/article/10.1007/s10980-015-0336-8 DOI: $10.1007 / \mathrm{s} 10980-015-0336-8$

191 implemented in ArcGis, to calculate LCD between each pair of habitat patches: LCD is the

192 accumulated cost distance of the most likely route an individual would take to move

193 between the two habitat patches considered. Only direct linkages between habitat patches

194 were considered to construct the habitat network model (see below). Using circuit theory

195 with Circuitscape (McRae et al. 2008; Shah and McRae 2008), we then calculated RD

196 between each pair of habitat patches (pairwise mode and connection option with eight

197 neighbours). Calculating RD was particularly time-consuming with a large numbers of

198 patches and linkages, because all the paths between two habitat patches have to be

199 considered. The resistance to current flow was therefore computed on the entire landscape

200 area, and for each pair of habitat patches. We were not interested in the precise location of

201 dispersal corridors, but in a measure of distance between habitat patches that took into

202 account alternative paths. Hence to calculate RD, we restricted the current flow analysis to a

203 corridor surrounding the least-cost path determined previously by applying a cut-off of

204700 m (cost width of corridor) and using an extension of Linkage Mapper that applied

205 Circuitscape in this specific way (McRae 2012). Consequently, all alternative paths not

206 exceeding $700 \mathrm{~m}$ from the least-cost path were kept to compute RD between a pair of

207 patches. When landscape impedes species movement, least-cost corridors are narrow and

208 there are few alternative paths between patches for species, so RD approximates to or

209 equals LCD, but when landscape is favourable to species movement, least-cost corridors are

210 wide and there are many alternative paths, making RD strongly shorter than LCD. In this

211 case, individuals have more chance of reaching the other habitat patch. We also calculated

212 RD for a corridor cut-off of $4000 \mathrm{~m}$ in order to verify how corridor cut-off could change the

213 estimation of habitat patch importance. Habitat patch importance for the two cut-offs was 
Author-produced version of the article published in Landscape Ecology, 2016, 31, 7, 1551-1565

The original publication is available at http://link.springer.com/article/10.1007/s10980-015-0336-8

DOI: $10.1007 / \mathrm{s} 10980-015-0336-8$

closely correlated: Spearman's rho was at least 0.92 , but generally above 0.94 for both

Region and Sub-region. We therefore kept RD based on a corridor cut-off of $700 \mathrm{~m}$ in what

follows. The calculation of LCD and RD for Sub-region was applied to the spatial extent of

Region (acting as a buffer, see Koen et al. 2010), to make the estimation of distance

independent of artificial boundary (only present at the North of Sub-region, see Material and Methods).

\section{Connectivity indices for evaluating habitat patch importance}

The habitat network model was composed of nodes representing habitat patches

characterized by their surface area, and of direct links representing linkages between habitat

patches characterized by their travel cost (LCD or RD). A set of connectivity indices was

calculated from the habitat network model with the free software Conefor 2.6 (Saura and

Torne 2009) in order to quantify the relative importance of habitat patches for global

network connectivity. Here we present the different indices used only briefly, all being

detailed and their use justified in an abundant literature. Moreover, our aim was not to

investigate the differences between connectivity indices (see Bodin and Saura 2010; Baranyi

et al. 2011), but to compare habitat patch ranking according to LCD-based linkages and RD-

based linkages for different connectivity indices currently used in the conservation biology

literature. A path or linkage is always the direct dispersal between two habitat patches (i.e.

with no other intermediate habitat patch), whereas the term pathway is used with a general meaning, i.e. dispersal ways in habitat network (direct or indirect). All connectivity indices

used in this study are given in Table 1. Betweenness Centrality (BC) considers the number of shortest pathways between all pair of nodes that go through a particular node, and so does 
Author-produced version of the article published in Landscape Ecology, 2016, 31, 7, 1551-1565

The original publication is available at http://link.springer.com/article/10.1007/s10980-015-0336-8 DOI: $10.1007 / \mathrm{s} 10980-015-0336-8$

not consider the node attribute (surface area). dIII $C_{\text {flux }}(\mathrm{dIICf}), \mathrm{dIIC} \mathrm{C}_{\text {connector }}(\mathrm{dIICc}), \mathrm{dPC} \mathrm{C}_{\text {flux }}(\mathrm{dPCf})$ and $\mathrm{dPC}_{\text {connector }}(\mathrm{dPC})$ are fractions resulting from the decomposition of the node importance value (dIIC, dPC) based on Integral Index of Connectivity (IIC) and on Probability of Connectivity (PC) respectively (Table 1). Flux fraction of a particular node (dIICf, dPCf) quantifies the amount of dispersal flux that occurs between the node and the rest of the network, and depends on the node attribute and the shortest pathways that link the node to the network (topological position). Connector fraction of a particular node (dIICc, dPCc) exists only if the shortest pathways between other nodes pass through the node, and so depends only on topological position; it quantifies the importance of the node as a steppingstone for dispersal, i.e. facilitating dispersal between excessively far nodes. We also computed the last fraction of node importance, the intra fraction (dIICi, dPCi) of a particular node, which depends only on the node attribute, and so has the same value whether the node is connected or not (see Saura and Rubio 2010). Investigating how the fractions connector and flux change with linkage type helped us to make a better evaluation of how connectivity models impact the importance of patch, and so support more precise recommendations for the use of prioritization methods. All indices were calculated for the nine dispersal distances and for the two landscapes. Dispersal distance acted as a threshold determining the presence of a link between two nodes in the case of binary indices (BC, dIICf, dIICC). In the case of probabilistic indices (dPCf, dPCC), dispersal distance determined the median probability associated with a link, defining the distance-decay constant $\alpha$ in the relation $p_{i j}=e^{-\alpha d_{i j}}$ (Urban and Keitt 2001; Saura and Pascual-Hortal 2007) where $p_{\mathrm{ij}}$ is the probability of dispersal between nodes $i$ and $j$, and $d_{i j}$ their distance (LCD or RD). BC, dlICf, dIICc, dPCf and dPCc have been shown to be non-redundant indicators of patch contribution in the maintaining of habitat network connectivity (Baranyi et al. 2011). Finally, we summed 
Author-produced version of the article published in Landscape Ecology, 2016, 31, 7, 1551-1565

The original publication is available at http://link.springer.com/article/10.1007/s10980-015-0336-8 DOI: $10.1007 / \mathrm{s} 10980-015-0336-8$

261

262

263

node importance values for each fraction flux, connector and intra over all the nodes, and then calculated the percentage of each sum relative to the total node importance values (Saura and Rubio 2010). This percentage was calculated for each dispersal distance in order to examine how habitat network connectivity (flux fraction and connector fraction of habitat network) changes according to LCD-based or RD-based indices. Connector fraction peaks when key stepping-stones become connected to habitat network, and flux fraction increases with connection of large habitat patches (high quality patches) and with the number of alternative pathways in the habitat network (Saura and Rubio 2010). We also calculated $\mathrm{BC}(\mathrm{IIC})$ and $\mathrm{BC}(\mathrm{PC})$, which are modifications of $\mathrm{BC}$ integrating properties of IIC and $\mathrm{PC}$ and are argued to be further useful indices (Bodin and Saura 2010), but we do not present the results for these indices since they were very closely correlated to dIICc and $\mathrm{dPCC}$ for both LCD and RD linkages (Spearman's rho was at least 0.91) and showed the same correlation pattern as dIICc and dPCc (see below).

\section{Comparison of LCD- and RD-based connectivity indices}

The higher the value of connectivity index, the greater the importance of the node for global habitat network connectivity. For each connectivity index and each dispersal distance, we compared node importance given by the LCD-based index to node importance given by the RD-based index by ranking importance values and applying rank correlation with Spearman's coefficient rho, which allowed control for extreme values and non-linear relationships. Only a limited number of habitat patches have a significant importance for the persistence of overall connectivity, and financial resources for nature conservation are generally restricted (e.g. Bodin and Saura 2010; Zetterberg et al. 2010; Gurrutxaga et al. 2011). Thus, after 
examining quantile distributions of index values, we kept only the 25 top-ranked habitat

285

286

287

288

289

290

291

292

293

294

295

296

297

298

299

300

301

302

303

304

patches according to the LCD-based index and the RD-based index in further analyses,

focusing on Sub-region, since results were closely similar at Region (see Supporting

Material). We identified in which cases habitat patches were top-ranked only by the LCD-

based index, only by the RD-based index and by both indices, and projected them on the habitat network map.

\section{Results}

\section{Habitat patch prioritization according to LCD-based and RD-based}

\section{indices}

Correlations between LCD-based indices and RD-based indices increased with dispersal distance for the two landscapes Sub-region and Region (Fig. 1 and Fig. S1). Correlations strongly increased from $200 \mathrm{~m}$ to $1000 \mathrm{~m}$, then increased more slowly up to $4000 \mathrm{~m}$, where Spearman's rho generally exceeded 0.9 , and were stable further away. For the smallest dispersal distances, a large part of LCD-based linkages was not established between habitat patches since linkage length exceeded the dispersal distance considered: $37.1 \%, 17.4 \%$, $13.5 \%$ and $2.9 \%$ of LCD-based linkages exceeded dispersal distance at $200 \mathrm{~m}, 700 \mathrm{~m}, 1000 \mathrm{~m}$ and $4000 \mathrm{~m}$ for Sub-region respectively $(27.1 \%, 12.3 \%, 8.8 \%, 1.7 \%$ for Region respectively). As expected, there were only a few cases where RD-based linkages exceeded the dispersal distance (2.6\% and $1.6 \%$ at $200 \mathrm{~m}$ for Sub-region and Region respectively). Hence habitat network models based on LCD and on RD strongly differed for small dispersal distances, 
Author-produced version of the article published in Landscape Ecology, 2016, 31, 7, 1551-1565

The original publication is available at http://link.springer.com/article/10.1007/s10980-015-0336-8 DOI: 10.1007/s10980-015-0336-8

while they became more similar with increasing dispersal distances. The sum of node importances reflected this convergence with increasing dispersal distances (Fig. 2 and Fig. S2). Differences persisted at slightly longer dispersal distances for probabilistic indices than for binary indices, particularly for connector fraction (Figs 1 and 2). The sum of node importances for Sub-region showed that dPCc peaked at $200 \mathrm{~m}$ and was rather stable from $1000 \mathrm{~m}$ when based on RD, but strongly decreased after $4000 \mathrm{~m}$ when based on LCD. By contrast, values of dIICc were similar at least from $4000 \mathrm{~m}$ for both distance types (same results for Region, Fig. S2). This difference occurred because for probabilistic indices, dispersal probability associated with the linkages increased much more rapidly when considering RD and alternative paths than when considering LCP and only one optimal path.

Figure 1. Correlation between habitat patch importance according to LCD-based and RD-based index for binary (a) and probabilistic indices (b) for Sub-region. Intra fraction (i), flux fraction (f) and connector fraction (f) are the partition of node importance dIIC and dPC. Tick marks without labels are 700, 1000 and 6000 m respectively.

Figure 2. Relative contribution of each fraction intra (i), flux (f), connector (c) to habitat network connectivity according to LCD-based and RD-based indices for Sub-region. Each fraction represents the contribution of all individual habitat patches relative to their total importance for maintaining connectivity. Tick marks without labels are 700, 1000 and $6000 \mathrm{~m}$ respectively.

The comparison of habitat patch ranking according to importance values given by LCD-based indices and by RD-based indices showed strong similarities (Fig. 3 and Fig. S3) that could be explained by strong correlations between connectivity indices for a type of linkages. First, the comparison of habitat patch ranking followed the same pattern for dIICf and dPCf, and their correlations were above 0.92 both for LCD-based and RD-based indices for Subregion (>0.9 for Region). Second, comparison showed the same pattern for dIICc and BC, and their correlation was above 0.91 for both LCD-based and RD-based indices for Sub-region ( $>0.92$ for LCD-based indices and $>0.87$ for RD-based indices for Region). The pattern was 
Author-produced version of the article published in Landscape Ecology, 2016, 31, 7, 1551-1565

The original publication is available at http://link.springer.com/article/10.1007/s10980-015-0336-8 DOI: 10.1007/s10980-015-0336-8

slightly different for dPCc and its correlation with other indices was lower ( $<0.8$ in all cases).

Indeed, three different cases occurred concerning habitat patch prioritization. Firstly, LCDbased indices gave a much higher importance to habitat patches than RD-based indices. The most illustrative case occurred when habitat patches had a moderate importance with LCDbased indices and had null importance (rank 1) with RD-based indices (see Fig. 3). Secondly, RD-based indices gave a much higher importance to habitat patches than LCD-based indices. The most illustrative case occurred when habitat patches had a moderate-to-high importance with RD-based indices and null importance with LCD-based indices. Thirdly, LCDbased and RD-based indices attributed closely similar importance value to habitat patches.

Figure 3. Habitat patch importance rank according to LCD-based versus RD-based indices for Sub-region. Minimal rank is attributed when several importance values are the same. Other dispersal distances are not shown. Circles illustrate some cases where prioritization strongly differed.

\section{Identification of top-ranked habitat patches}

We focused on the 25 habitat patches with the greatest contribution for maintaining global habitat network connectivity at Sub-region level and projected the three different cases on the habitat network map. From the 700-m dispersal distance, almost the same habitat patches were identified by IICf and PCf based on LCD or RD linkages, whereas they strongly differed until the 1000-m dispersal distance for BC and IICc (Figs 4 and 5). The prioritization of habitat patches by $\mathrm{dPC}$ remained divergent even when considering large dispersal distances, and only about $50 \%$ of top-ranked habitat patches were identified by both index types whatever the distance (Fig. 4). This means that when connectivity indices were weighted by patch attributes (IICf and PCf), linkage type had very little importance for patch 
Author-produced version of the article published in Landscape Ecology, 2016, 31, 7, 1551-1565

The original publication is available at http://link.springer.com/article/10.1007/s10980-015-0336-8 DOI: 10.1007/s10980-015-0336-8

353

prioritization in our study, but it had high importance when connectivity indices were based only on dispersal distance for short- and medium-distance dispersers (BC and IICC) or when they were based on dispersal probability (dPCc). In certain cases for binary indices, habitat patches were top-ranked by the RD-based index, whereas the LCD-based index gave them a null importance as habitat patches were at one end or totally isolated in the LCD-based habitat network (see arrow 1 on Fig. 5). However, in other cases, habitat patches were topranked only by the RD-based index, although they might have been expected to be topranked also by the LCD-based index (arrows 2, Fig. 5): the loss of these habitat patches seriously affected dispersal between group of patches and the rest of the LCD-based habitat network for short-distance and medium-distance dispersers, because there was no alternative pathway, or only much longer pathways with many intermediate steps. LCDbased indices evaluated other habitat patches as being more important for network connectivity (e.g. arrows 3 on Fig. 5), their loss causing the total isolation of a large part of the habitat network. However, RD linkages showed several alternative pathways with an equivalent or smaller number of steps, thus providing other connections with the rest of the habitat network. Consequently, LCD-based indices tended to overestimate the role of certain habitat patches compared with RD-based indices, because they seemed to act as key connectors for maintaining habitat network connectivity whereas alternative pathways existed (see Figs 5 and 6). This resulted in a decrease in the importance of the other habitat patches identified as key-elements by RD-based indices.

Figure 4. Among the 25 top-ranked habitat patches, number of patches identified commonly by LCD-based and RD-based indices.

Figure 5. Map showing the 25 top-ranked habitat patches according to dlICc for a maximum dispersal distance of $1000 \mathrm{~m}$. Top-ranked patches only by RD-based (green), only by LCD-based (orange) and by both indices (lilac), other habitat patches 
on LCD strongly differed from habitat network based on RD for small and medium dispersal

7b). There were alternative pathways with high dispersal probabilities since large corridors and different paths between patches could be used by individuals to disperse (Fig. S4).

\section{Discussion}

We report evidence that there was strong divergence between habitat patch prioritization based on linkage reflecting the least-cost path and that based on linkage reflecting multiple paths, depending on the type of connectivity indices and species dispersal distance. The 
Author-produced version of the article published in Landscape Ecology, 2016, 31, 7, 1551-1565

The original publication is available at http://link.springer.com/article/10.1007/s10980-015-0336-8 DOI: 10.1007/s10980-015-0336-8

400

401

402

403

404

405

406

407

408

409

410

411

412

413

same patterns of prioritization occurred for both landscapes Region and Sub-region, which

strongly differed in terms of spatial extent, landscape composition and fragmentation. This suggests that the correlation patterns we found in this study may not depend on landscape extent and landscape structure. However, further investigations are needed to measure to what extent the correlation between LCP-based prioritization and RD-based prioritization will follow the same pattern when landscape structure changes. Prioritization indices are presented as tools helping practitioners to orientate field conservation measures by the use of available knowledge about dispersal capacities and species requirements (Galpern et al. 2011), since it is not (or only rarely) possible to obtain robust data on real species fluxes between habitat patches at large scales. Hence, the use of prioritization indices and leastcost corridors or current maps identifying potential key landscape areas is an important advance for landscape and species conservation management (Beier et al. 2011; Lawler et al. 2013; Ayram et al. 2014). LCD and RD are methods with marked conceptual differences, and we showed that the way they influence prioritization of landscape features is not trivial.

LCD-based and RD-based indices identified almost the same habitat patches even for short dispersal (from $700 \mathrm{~m}$ ) when considering the role of patches as providers (or receivers) of individual fluxes. Habitat patch attribute weighted the influence of distance type, and when large habitat patches were well connected to the habitat network (mean patch area was 178 ha for Sub-region but 3140 ha for the 25 top-ranked habitat patches by dlICf or dPCf), it was sufficient to calculate LCD to properly quantify the importance of habitat patches for dispersal fluxes into the habitat network. Accordingly, we recommend that conservation managers calculate only LCD in a first line approach, and then verify the degree of connection between large (high quality) habitat patches and the rest of the habitat 
Author-produced version of the article published in Landscape Ecology, 2016, 31, 7, 1551-1565

The original publication is available at http://link.springer.com/article/10.1007/s10980-015-0336-8 DOI: 10.1007/s10980-015-0336-8

423

424

network before deciding whether the calculation of RD is required for quantifying the contribution of patches to dispersal fluxes at the scale of the landscape.

Concerning the role of habitat patches as stepping-stones, i.e. facilitating species dispersal between far habitat patches, the choice of RD or LCD could depend on the assumptions about how the species population functions. Considering the presence or absence of the linkage, i.e. the use of binary indices (BC, dIICC), almost all linkages were established for LCP above a certain dispersal distance of the species. In one study on a plant species (Neel 2008), IIC tended to explain genetic differences between populations better than PC, but for a Euclidean distance less than $2500 \mathrm{~m}$, so actually a much shorter distance than in our study. If we hypothesize that one individual would be sufficient to change the genetic structure of population (see Wang 2004), the convergence of patch prioritization based on LCD and on RD should be expected. LCD indicated the minimum distance a particular individual had to move between habitat patches, and when the individual dispersal capacity was at least LCD, the individual was able to move to any population patch. Accordingly, our results show that the calculation of RD did not provide any further information about key stepping stones in the landscape.

When considering the linkage probability between habitat patches (dPCc), strong differences remained whatever the dispersal distance. RD considered the probability of dispersal between habitat patches taking into account path redundancy, i.e. it indicated the resistance distance one species moved between population patches (Fletcher et al. 2014). $\mathrm{RD}$ can be more closely correlated with genetic distance compared with $\mathrm{LCP}$, which implies that taking into account the flux of dispersers better reflects genetic differences between populations than considering one (best) disperser (McRae and Beier 2007). Consequently, 
Author-produced version of the article published in Landscape Ecology, 2016, 31, 7, 1551-1565

The original publication is available at http://link.springer.com/article/10.1007/s10980-015-0336-8 DOI: 10.1007/s10980-015-0336-8

446

447

448

449

450

451

452

we can hypothesize that RD-based dPCc predicts functional connectivity between

populations better than LCD-based dPCc, since the establishment of linkages between

patches is proportional to the number of dispersers, and not only to the inter-patch distance

(Fletcher et al. 2014). The current map (Fig. S4) illustrates the differentiation of narrow

corridors for forest species dispersal (pinchpoints), versus large corridors or alternative paths between habitat patches that increase the probability of dispersal for the species (compare dispersal probability in Figs 7a and 7b).

Future studies will use genetic data to corroborate that RD best identifies key landscape elements that contribute to the long-term persistence of species. Our results also show that LCD-based dPCc allowed the identification of landscape parts that remain difficult to reach for one individual because of a strong impedance of the surrounding landscape: restoration actions to facilitate individual dispersal will ameliorate the connectivity with other landscape parts, and probably also the long-term persistence of the species. Habitat patch importance was evaluated similarly according to RD based on 700-m corridor cut-off and 4000-m corridor cut-off, but if RD was calculated considering the entire surrounding landscape as space for dispersal movements, the prioritization differences between LCD and RD might be accentuated. Our results suggest that resistance-based connectivity is substantially affected by different conceptual approaches and not only by the way resistance values are parameterized (Mateo-Sanchez et al. 2015). Importantly, these approaches do not replace species monitoring or genetic studies nor finer-scaled investigations before protection or restoration actions are attempted. 


\section{Acknowledgments}

469 C.A. was supported by Region PACA (APRF 2011 projet Alterbio PACA) and Irstea. 


\section{$471 \quad$ Table 1}

472 Table 1. Binary and probabilistic connectivity indices used for prioritization of habitat

\section{patches in our study}

\begin{tabular}{|c|c|c|c|c|}
\hline & INDEX & TYPE & MEANING & REFERENCES \\
\hline BC & $\begin{array}{r}\text { Betweenness } \\
\text { Centrality }\end{array}$ & Binary & $\begin{array}{l}\text { Considers the role of patch } i \text { as connecting other patches } \\
\text { (stepping-stone) with shortest pathways }\end{array}$ & $\begin{array}{r}\text { Estrada and Bodin } \\
\text { 2008; Bodin and } \\
\text { Saura } 2010\end{array}$ \\
\hline dIIC & delta IIC & Binary & $\begin{array}{l}\text { Importance of patch } i \text { according to Integral Index of } \\
\text { Connectivity. IIC considers both habitat amount and habitat } \\
\text { reachability in habitat network, and linkages as dispersal events } \\
\text { between patches. dIIC quantifies the loss of connectivity if patch } \\
i \text { is removed from habitat network and can be decomposed into } \\
\text { dIICf, dIICc, dIICi }\end{array}$ & $\begin{array}{r}\text { Urban and Keitt 2001; } \\
\text { Pascual-Hortal } \\
\text { and Saura 2006; } \\
\text { Saura and Rubio 2010 }\end{array}$ \\
\hline $\mathrm{dPC}$ & delta PC & Probabilistic & $\begin{array}{l}\text { Importance of patch } i \text { according to Probability of Connectivity. } \\
\text { Like IIC, PC considers both habitat amount and habitat } \\
\text { reachability in habitat network, but the probability of dispersal } \\
\text { between patches. dPC can also be decomposed into dPCf, dPCc, } \\
\text { dPCi }\end{array}$ & $\begin{array}{l}\text { Saura and Pascual- } \\
\text { Hortal 2007; Saura } \\
\text { and Rubio } 2010\end{array}$ \\
\hline $\begin{array}{l}\text { dlICf } \\
\text { dPCf }\end{array}$ & $\begin{array}{r}\text { Flux fraction } \\
\text { of dIIC } \\
\text { of } d P C\end{array}$ & $\begin{array}{r}\text { Binary } \\
\text { Probabilistic }\end{array}$ & $\begin{array}{l}\text { Quantifies the role of patch } i \text { as receiving (emitting) flux from } \\
\text { (to) other patches. It considers the attributes of } i \text { and of other } \\
\text { patches, and the shortest pathways between them }\end{array}$ & Saura and Rubio 2010 \\
\hline $\begin{array}{l}\text { dIICc } \\
\text { dPCc }\end{array}$ & $\begin{array}{r}\text { Connector fraction } \\
\text { of dIIC } \\
\text { of } \mathrm{dPC}\end{array}$ & $\begin{array}{r}\text { Binary } \\
\text { Probabilistic }\end{array}$ & $\begin{array}{l}\text { Quantifies the role of patch } i \text { as connecting other patches } \\
\text { (stepping-stone). It considers shortest pathways passing through } \\
i \text { and the attribute of other patches }\end{array}$ & $\begin{array}{r}\text { Saura and Rubio } \\
\text { 2010; Gurrutxaga et } \\
\text { al. 2011; Saura et al. } \\
2014\end{array}$ \\
\hline $\begin{array}{l}\text { dIICi } \\
\text { dPCi }\end{array}$ & $\begin{array}{r}\text { Intra fraction } \\
\text { of dIIC } \\
\text { of } d P C \\
\end{array}$ & $\begin{array}{r}\text { Binary } \\
\text { Probabilistic } \\
\end{array}$ & $\begin{array}{l}\text { Quantifies the role of patch } i \text { as providing intra-connectivity so } \\
\text { considering only the attribute of } i \text {. }\end{array}$ & Saura and Rubio 2010 \\
\hline
\end{tabular}

474 


\section{Figure Captions}

477 Figure 1. Correlation between habitat patch importance according to LCD-based and RDbased index for binary (a) and probabilistic indices (b) for Sub-region. Intra fraction (i), flux fraction ( $f$ ) and connector fraction ( $f$ ) are the partition of node importance dIIC and APC. Tick marks without labels are 700, 1000 and 6000 m respectively.

Figure 2. Relative contribution of each fraction intra (i), flux (f), connector (c) to habitat $\mathrm{m}$ respectively.

Figure 3. Habitat patch importance rank according to LCD-based versus RD-based indices for

487 Sub-region. The higher the patch importance, the higher the rank. Minimal rank is attributed when several importance values are the same. Other dispersal distances are not shown. Circles illustrate some cases where prioritization strongly differed.

Figure 4. Among the 25 top-ranked habitat patches, number of patches identified by both LCD-based and RD-based indices.

Figure 5. Map showing the 25 top-ranked habitat patches according to dIICc for a maximum

493 dispersal distance of $1000 \mathrm{~m}$. Top-ranked patches only by RD-based (green), only by LCD-

494 based (orange) and by both indices (lilac), other habitat patches in grey. Difference between

495 LCD-based rank and RD-based rank in bold. Linkages are established when RD $\leq 1000 \mathrm{~m}$ (red 496 and green); and in fewer cases when LCD $\leq 1000 \mathrm{~m}$ (red). Numbered arrows indicate three 497 typical cases resulting from the difference in patch prioritization (see Results). 
498 Figure 6. Maps showing the 25 top-ranked habitat patches according to dPCc for the 6000-m

499 median dispersal distance. LCD-based (a) and RD-based linkages (b) are represented

500 according to their dispersal probability. See Fig. 5 for other details.

501 Figure 7. Maps showing the 25 top-ranked habitat patches according to dPCc for the $25-\mathrm{km}$

502 median dispersal distance. LCD-based (a) and RD-based linkages (b) are represented

503 according to their dispersal probability. See Fig. 5 for other details. 
Author-produced version of the article published in Landscape Ecology, 2016, 31, 7, 1551-1565

The original publication is available at http://link.springer.com/article/10.1007/s10980-015-0336-8

DOI: $10.1007 / \mathrm{s} 10980-015-0336-8$

\section{Figures}

\section{Figure 1}
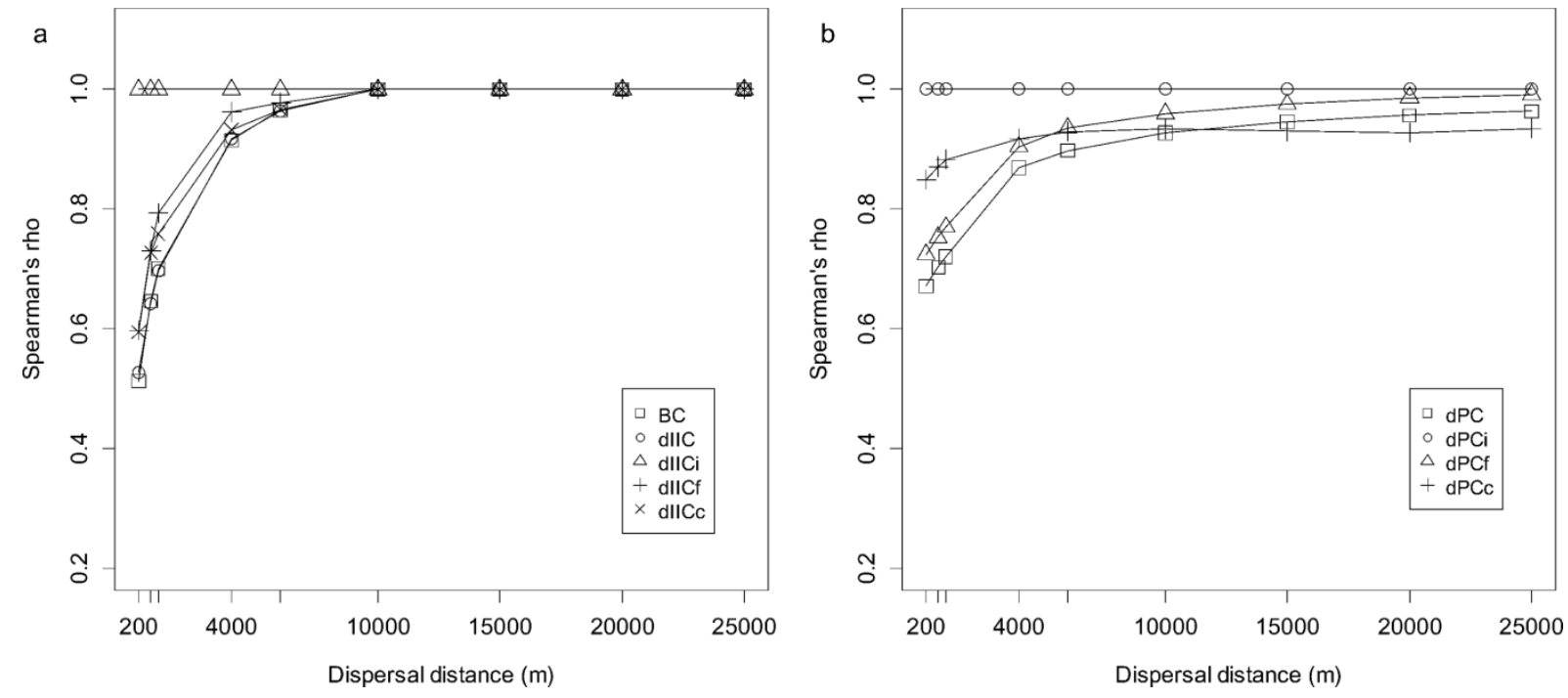

508 
Author-produced version of the article published in Landscape Ecology, 2016, 31, 7, 1551-1565

The original publication is available at http://link.springer.com/article/10.1007/s10980-015-0336-8

DOI: 10.1007/s10980-015-0336-8

\section{Figure 2}
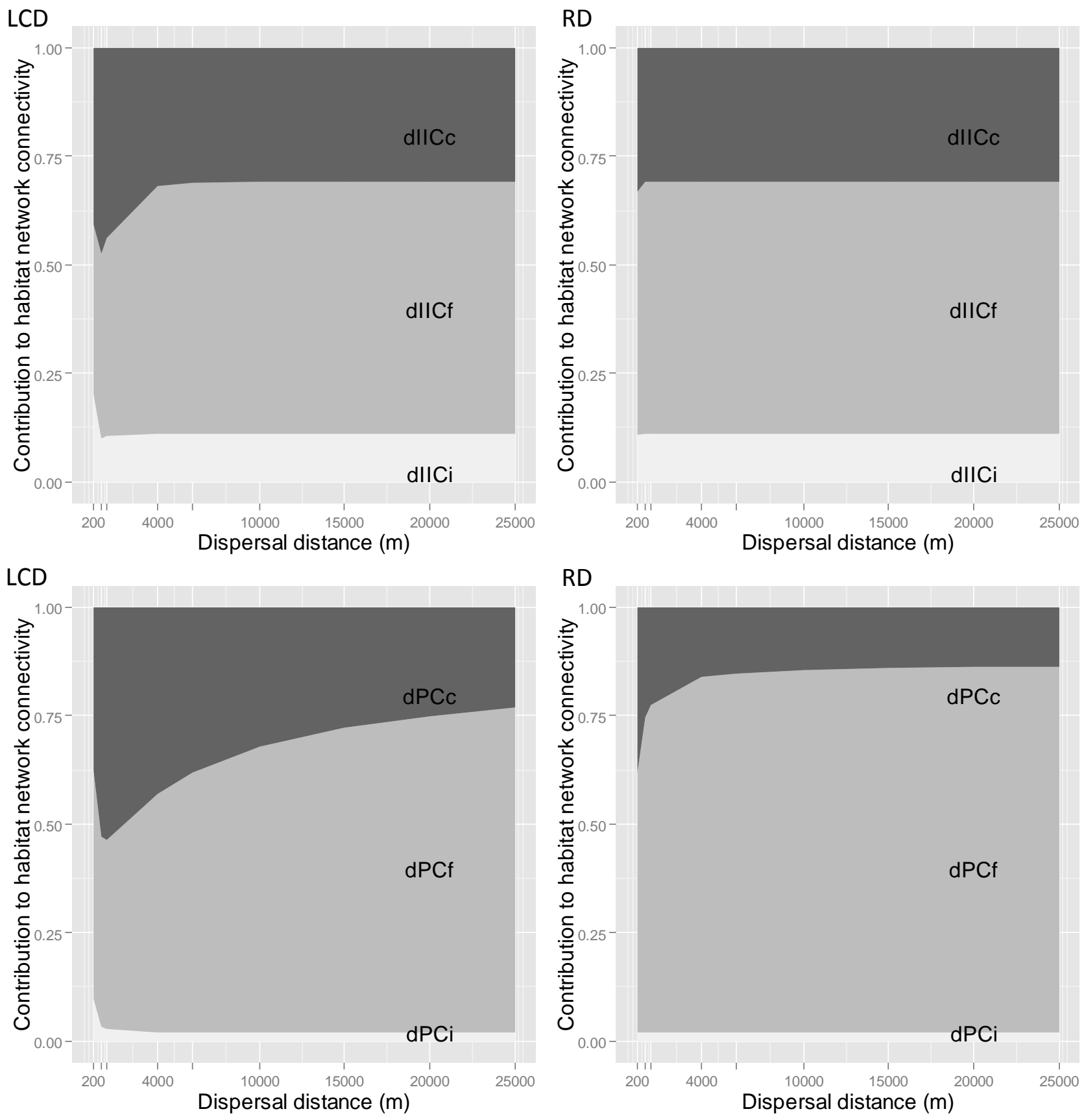


\section{Figure 3}
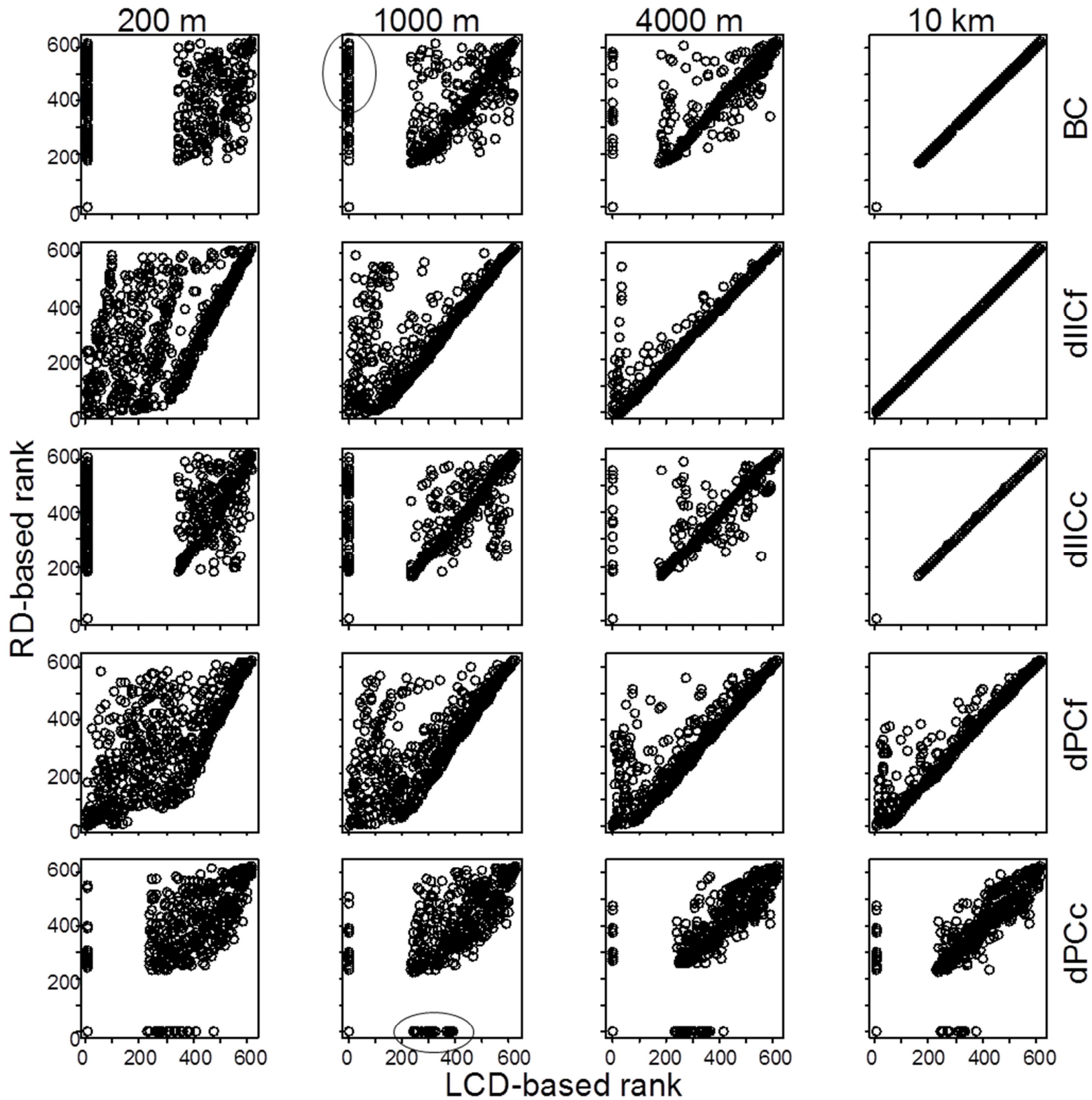


\section{$514 \quad$ Figure 4}

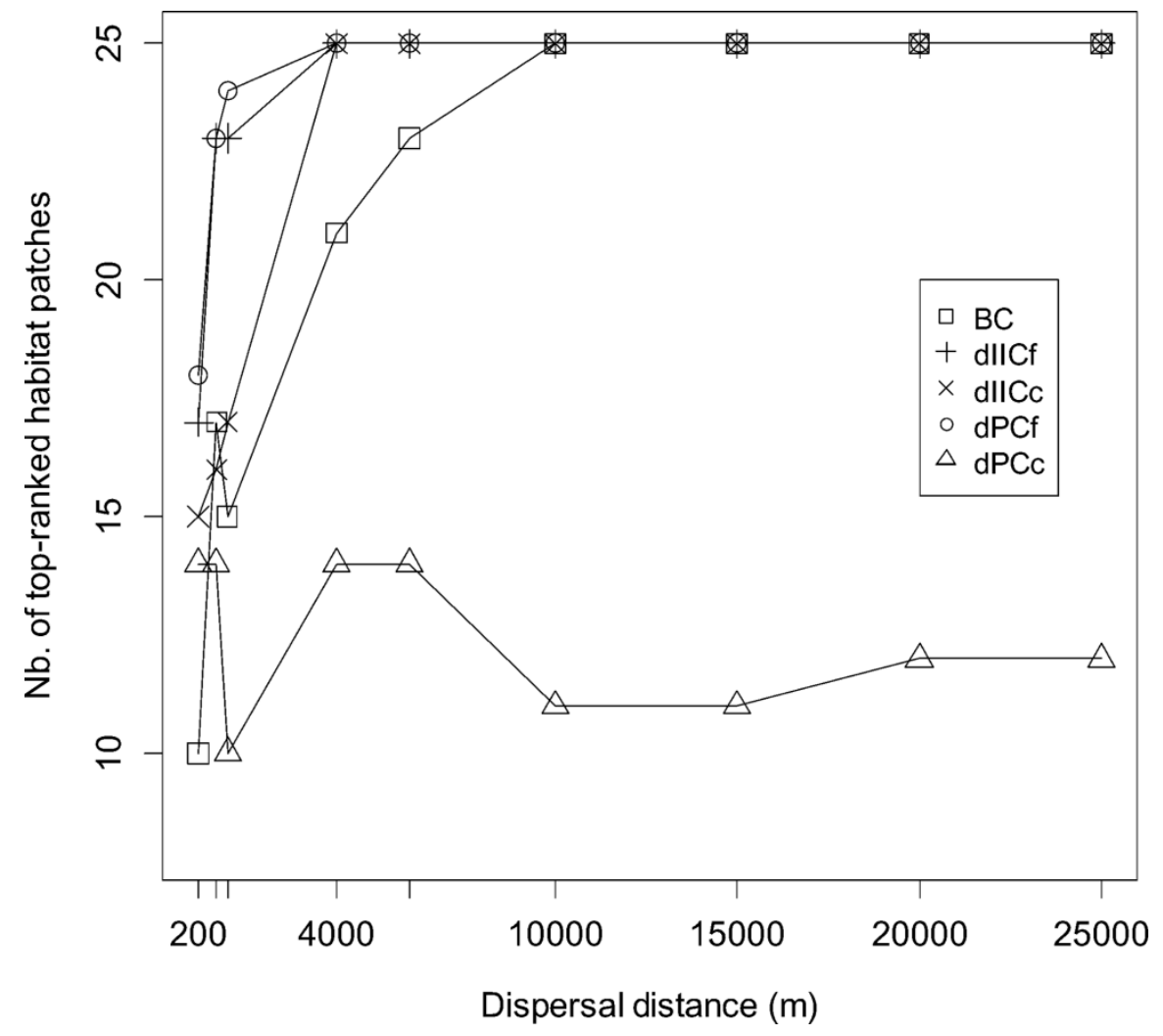

516 
Author-produced version of the article published in Landscape Ecology, 2016, 31, 7, 1551-1565 The original publication is available at http://link.springer.com/article/10.1007/s10980-015-0336-8 DOI: $10.1007 / \mathrm{s} 10980-015-0336-8$

Figure 5

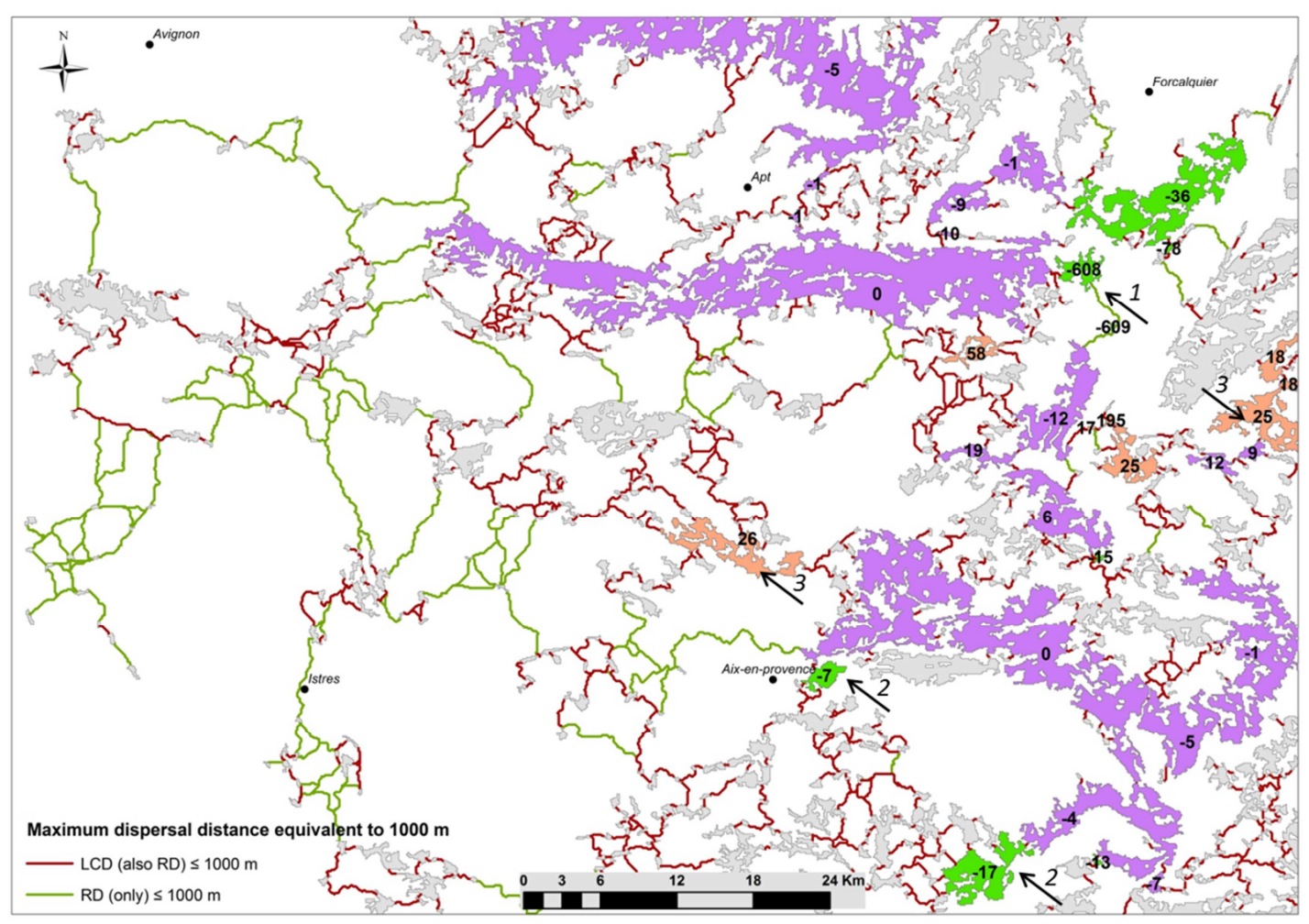


Author-produced version of the article published in Landscape Ecology, 2016, 31, 7, 1551-1565 The original publication is available at http://link.springer.com/article/10.1007/s10980-015-0336-8 DOI: 10.1007/s10980-015-0336-8

a

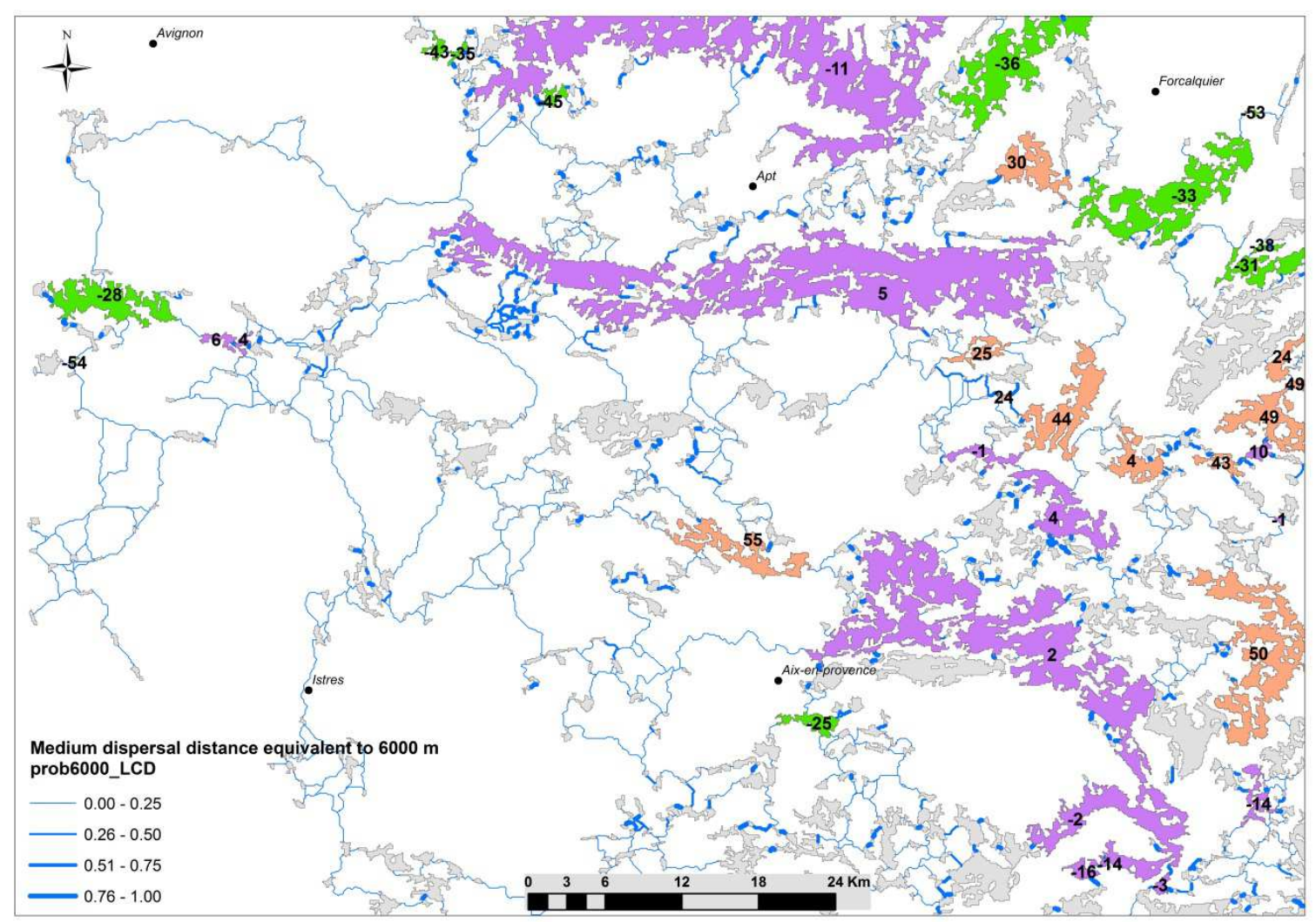

b

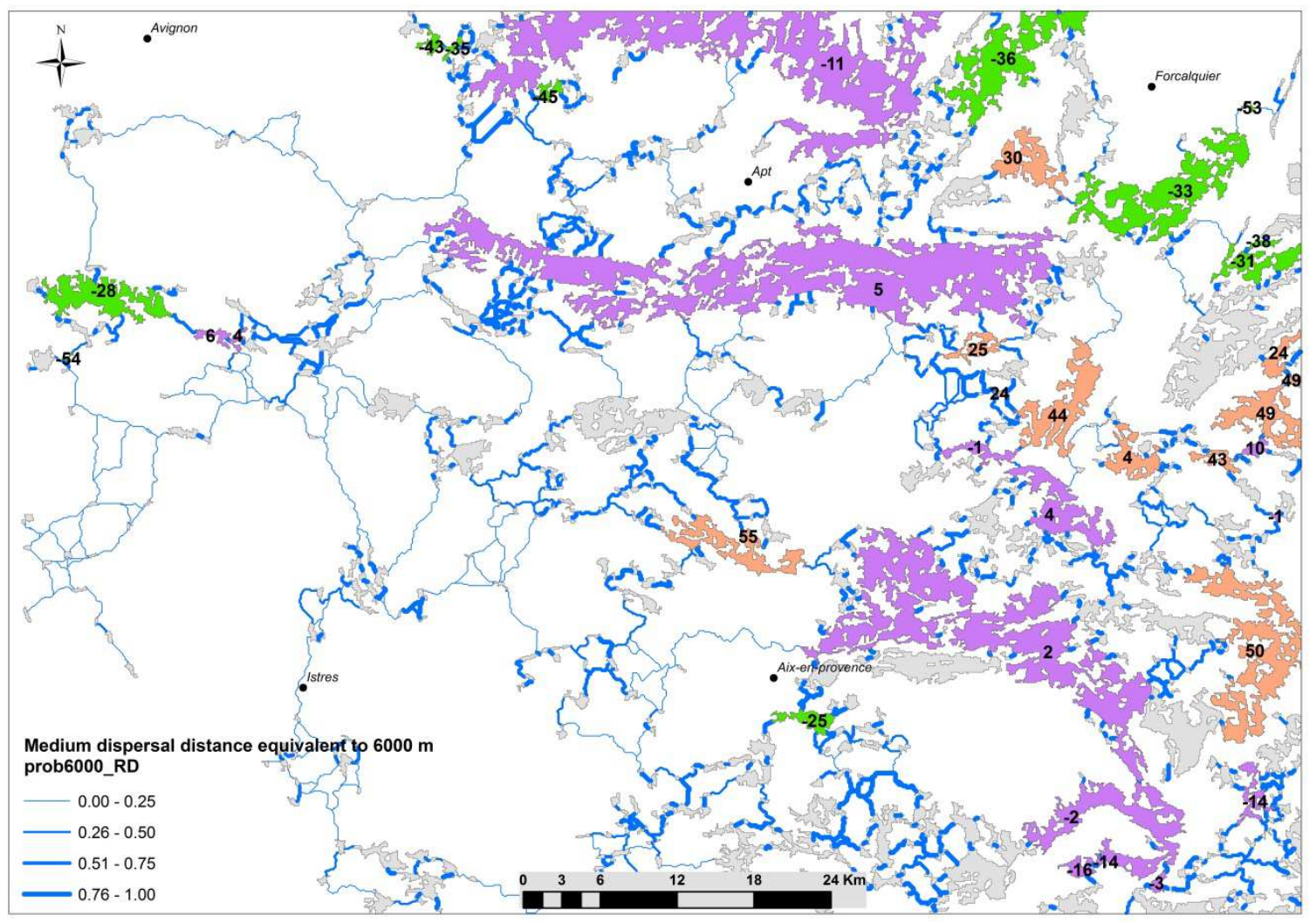


Author-produced version of the article published in Landscape Ecology, 2016, 31, 7, 1551-1565 The original publication is available at http://link.springer.com/article/10.1007/s10980-015-0336-8 DOI: 10.1007/s10980-015-0336-8

a

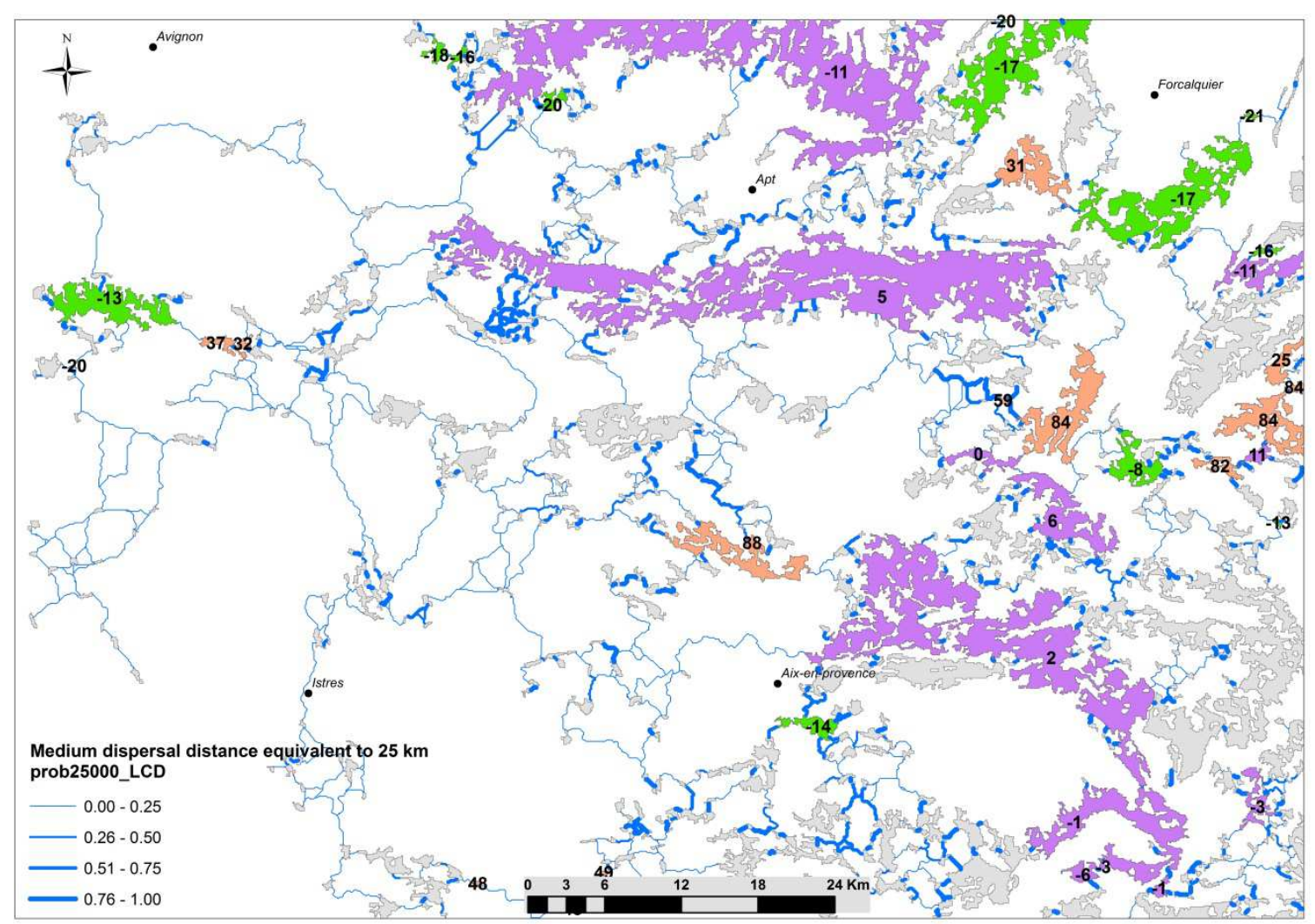

b

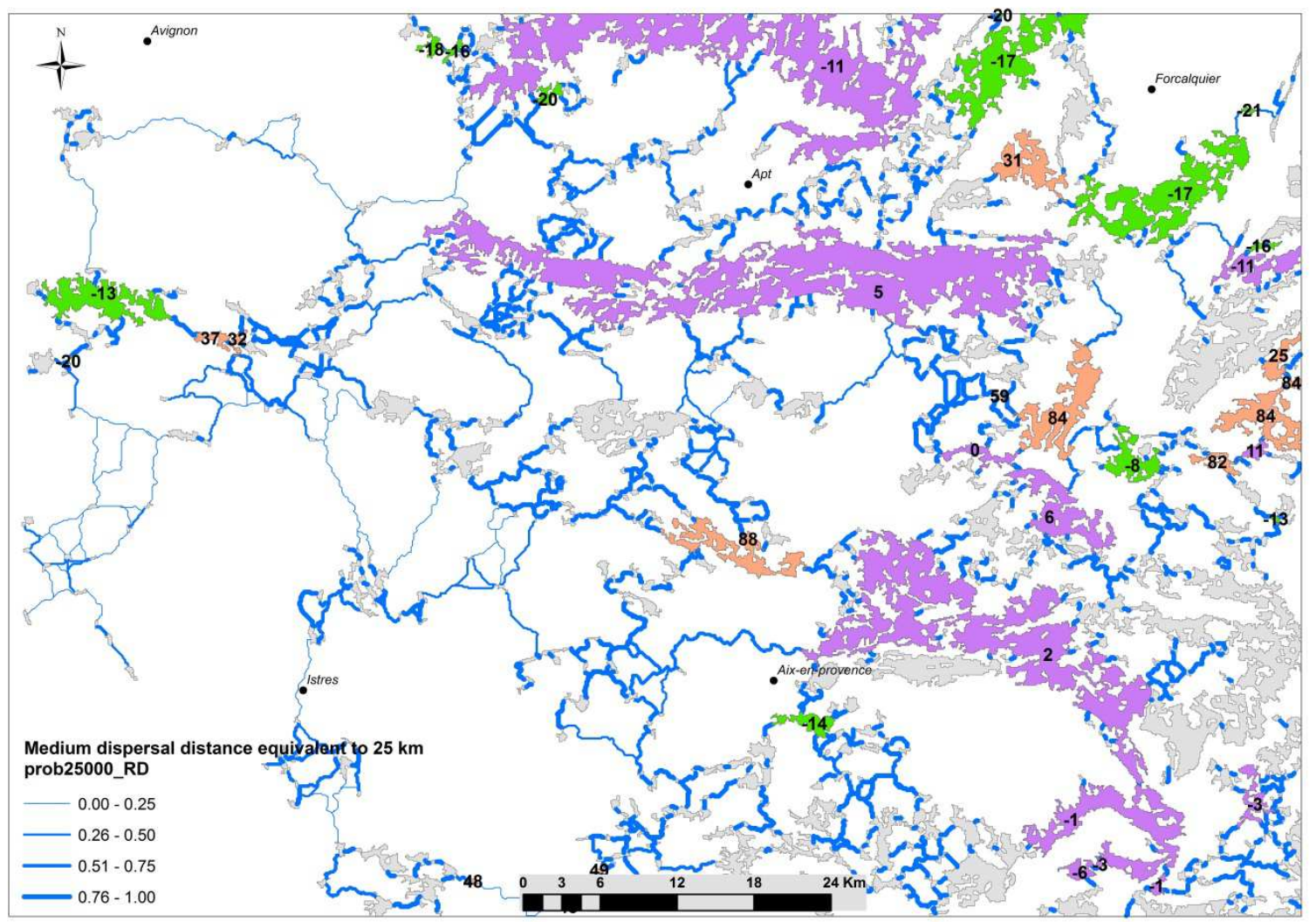




\section{Supporting Material Captions}

528 Figure S1. Correlation between habitat patch importance according to LCD-based and RD-

529 based index for binary and probabilistic indices for Region.

530 Figure S2. Relative contribution of each fraction intra, flux and connector to habitat network

531 connectivity according to LCD-based and RD-based indices for Region.

532 Figure S3. Habitat patch importance rank according to LCD-based versus RD-based indices

533 for Region.

534 Figure S4. Current intensity map represented areas with high density of dispersal flux, taking 535 into account alternative paths for Sub-region. 


\section{References}

Adriaensen F, Chardon JP, De Blust G, Swinnen E, Villalba S, Gulinck H, Matthysen E (2003)

The application of 'least-cost' modelling as a functional landscape model. Landscape Urban

542 Amos JN, Harrisson KA, Radford JQ, White M, Newell G, Mac Nally R, Sunnucks P, Pavlova A

543 (2014) Species- and sex-specific connectivity effects of habitat fragmentation in a suite of

544 woodland birds. Ecology 95(6):1556-1568

545 Ayram CAC, Mendoza ME, Salicrup DRP, Granados EL (2014) Identifying potential

546 conservation areas in the Cuitzeo Lake basin, Mexico by multitemporal analysis of landscape

547 connectivity. J. Nat. Conserv. 22(5):424-435

548 Baranyi G, Saura S, Podani J, Jordan F (2011) Contribution of habitat patches to network 549 connectivity: Redundancy and uniqueness of topological indices. Ecol Indic 11(5):1301-1310 550 Beier P, Spencer W, Baldwin RF, McRae BH (2011) Toward Best Practices for Developing

551 Regional Connectivity Maps. Conserv Biol 25(5):879-892

552 Belisle M (2005) Measuring landscape connectivity: The challenge of behavioral landscape

553 ecology. Ecology 86(8):1988-1995

554 Bodin O, Saura S (2010) Ranking individual habitat patches as connectivity providers:

555 Integrating network analysis and patch removal experiments. Ecol Model 221(19):2393-2405

556 Clauzel C, Girardet X, Foltete JC (2013) Impact assessment of a high-speed railway line on 557 species distribution: Application to the European tree frog (Hyla arborea) in Franche-Comte. 558 J Environ Manage 127:125-134 
Author-produced version of the article published in Landscape Ecology, 2016, 31, 7, 1551-1565

The original publication is available at http://link.springer.com/article/10.1007/s10980-015-0336-8 DOI: $10.1007 / \mathrm{s} 10980-015-0336-8$

559 Didham RK, Kapos V, Ewers RM (2012) Rethinking the conceptual foundations of habitat

560 fragmentation research. Oikos 121(2):161-170

561 Ernst BW (2014) Quantifying landscape connectivity through the use of connectivity

562 response curves. Landscape Ecol 29(6):963-978

563 Estrada E, Bodin O (2008) Using network centrality measures to manage landscape

564 connectivity. Ecol Appl 18(7):1810-1825

565 Fletcher RJ, Acevedo MA, Robertson EP (2014) The matrix alters the role of path redundancy

566 on patch colonization rates. Ecology 95(6):1444-1450

567 Foltete JC, Girardet X, Clauzel C (2014) A methodological framework for the use of landscape

568 graphs in land-use planning. Landscape Urban Plan 124:140-150

569 Galpern P, Manseau M, Fall A (2011) Patch-based graphs of landscape connectivity: A guide

570 to construction, analysis and application for conservation. Biol Conserv 144(1):44-55

571 Garcia-Feced C, Saura S, Elena-Rossello R (2011) Improving landscape connectivity in forest

572 districts: A two-stage process for prioritizing agricultural patches for reforestation. Forest

573 Ecol Manag 261(1):154-161

574 Gimona A, Poggio L, Brown I, Castellazzi M (2012) Woodland networks in a changing climate:

575 Threats from land use change. Biol Conserv 149(1):93-102

576 Gurrutxaga M, Rubio L, Saura S (2011) Key connectors in protected forest area networks and

577 the impact of highways: A transnational case study from the Cantabrian Range to the

578 Western Alps (SW Europe). Landscape Urban Plan 101(4):310-320

579 Gurrutxaga M, Saura S (2014) Prioritizing highway defragmentation locations for restoring

580 landscape connectivity. Environ Conserv 41(2):157-164

581 Koen EL, Bowman J, Walpole AA (2012) The effect of cost surface parameterization on

582 landscape resistance estimates. Molecular Ecology Resources 12(4):686-696 
583 Koen EL, Garroway CJ, Wilson PJ, Bowman J (2010) The Effect of Map Boundary on Estimates

584 of Landscape Resistance to Animal Movement. Plos One 5(7)

585 LaPoint S, Gallery P, Wikelski M, Kays R (2013) Animal behavior, cost-based corridor models,

586 and real corridors. Landscape Ecol 28(8):1615-1630

587 Lawler JJ, Ruesch AS, Olden JD, McRae BH (2013) Projected climate-driven faunal movement 588 routes. Ecol Lett 16(8):1014-1022

589 Marrotte RR, Gonzalez A, Millien V (2014) Landscape resistance and habitat combine to 590 provide an optimal model of genetic structure and connectivity at the range margin of a

591 small mammal. Mol Ecol 23(16):3983-3998

592 Mateo-Sanchez MC, Balkenhol N, Cushman S, Perez T, Dominguez A, Saura S (2015)

593 Estimating effective landscape distances and movement corridors: comparison of habitat

594 and genetic data. Ecosphere 6(4)

595 McRae BH (2012) Pinchpoint Mapper Connectivity Analysis Software. The Nature

596 Conservancy, Seattle WA

597 McRae BH, Beier P (2007) Circuit theory predicts gene flow in plant and animal populations.

$598 \quad$ P Natl Acad Sci USA 104(50):19885-19890

599 McRae BH, Dickson BG, Keitt TH, Shah VB (2008) Using Circuit Theory to Model Connectivity

600 in Ecology, Evolution, and Conservation. Ecology 89(10):2712-2724

601 McRae BH, Kavanagh DM (2011) Linkage Mapper Connectivity Analysis Software. The Nature 602 Conservancy, Seattle WA

603 Neel MC (2008) Patch connectivity and genetic diversity conservation in the federally 604 endangered and narrowly endemnoc plant species Astragalms albens (Fabaceae). Biol

605 Conserv 141(4):938-955 
Author-produced version of the article published in Landscape Ecology, 2016, 31, 7, 1551-1565

The original publication is available at http://link.springer.com/article/10.1007/s10980-015-0336-8 DOI: 10.1007/s10980-015-0336-8

606 Pascual-Hortal L, Saura S (2006) Comparison and development of new graph-based

607 landscape connectivity indices: towards the priorization of habitat patches and corridors for

608 conservation. Landscape Ecol 21(7):959-967

609 Pinto N, Keitt TH (2009) Beyond the least-cost path: evaluating corridor redundancy using a

610 graph-theoretic approach. Landscape Ecol 24(2):253-266

611 Poor EE, Loucks C, Jakes A, Urban DL (2012) Comparing Habitat Suitability and Connectivity

612 Modeling Methods for Conserving Pronghorn Migrations. Plos One 7(11)

613 Rayfield B, Fortin MJ, Fall A (2011) Connectivity for conservation: a framework to classify

614 network measures. Ecology 92(4):847-858

615 Roever CL, van Aarde RJ, Leggett K (2013) Functional connectivity within conservation

616 networks: Delineating corridors for African elephants. Biol Conserv 157:128-135

617 Rowcliffe JM, Carbone C, Kays R, Kranstauber B, Jansen PA (2012) Bias in estimating animal

618 travel distance: the effect of sampling frequency. Methods Ecol Evol 3(4):653-662

619 Saura S, Bodin O, Fortin MJ (2014) Stepping stones are crucial for species' long-distance

620 dispersal and range expansion through habitat networks. J Appl Ecol 51(1):171-182

621 Saura S, Pascual-Hortal L (2007) A new habitat availability index to integrate connectivity in

622 landscape conservation planning: Comparison with existing indices and application to a case

623 study. Landscape Urban Plan 83(2-3):91-103

624 Saura S, Rubio L (2010) A common currency for the different ways in which patches and links

625 can contribute to habitat availability and connectivity in the landscape. Ecography 33(3):523-

$626 \quad 537$

627 Saura S, Torne J (2009) Conefor Sensinode 2.2: A software package for quantifying the

628 importance of habitat patches for landscape connectivity. Environ Modell \& Softw 24(1):135-

$629 \quad 139$ 
630 Shah VB, McRae BH Circuitscape: a tool for landscape ecology. In: Varoquaux G., Vaught, T.,

631 Millman, J. (ed) Proceedings of the 7th Python in Science Conference (SciPy 2008), 2008. pp.

$632 \quad 62-66$

633 Stevens VM, Verkenne C, Vandewoestijne S, Wesselingh RA, Baguette M (2006) Gene flow

634 and functional connectivity in the natterjack toad. Mol Ecol 15(9):2333-2344

635 Urban D, Keitt T (2001) Landscape connectivity: A graph-theoretic perspective. Ecology

636 82(5):1205-1218

637 Urban DL, Minor ES, Treml EA, Schick RS (2009) Graph models of habitat mosaics. Ecol Lett

$638 \quad 12(3): 260-273$

639 Verbeylen G, De Bruyn L, Adriaensen F, Matthysen E (2003) Does matrix resistance influence

640 Red squirrel (Sciurus vulgaris L. 1758) distribution in an urban landscape? Landscape Ecol

641 18(8):791-805

642 Wang JL (2004) Application of the one-migrant-per-generation rule to conservation and

643 management. Conserv Biol 18(2):332-343

644 Watts K, Eycott AE, Handley P, Ray D, Humphrey JW, Quine CP (2010) Targeting and

645 evaluating biodiversity conservation action within fragmented landscapes: an approach

646 based on generic focal species and least-cost networks. Landscape Ecol 25(9):1305-1318

647 Wauters LA, Verbeylen G, Preatoni D, Martinoli A, Matthysen E (2010) Dispersal and habitat

648 cuing of Eurasian red squirrels in fragmented habitats. Popul Ecol 52(4):527-536

649 Zeller KA, McGarigal K, Whiteley AR (2012) Estimating landscape resistance to movement: a

650 review. Landscape Ecol 27(6):777-797

651 Zetterberg A, Mortberg UM, Balfors B (2010) Making graph theory operational for landscape

652 ecological assessments, planning, and design. Landscape Urban Plan 95(4):181-191 
Author-produced version of the article published in Landscape Ecology, 2016, 31, 7, 1551-1565 The original publication is available at http://link.springer.com/article/10.1007/s10980-015-0336-8 DOI: 10.1007/s10980-015-0336-8

654 